Case Study

\title{
Sustainability evaluation and spatial heterogeneity of urban agglomerations: a China case study
}

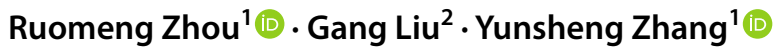

Received: 27 October 2020 / Accepted: 26 January 2021

(c) The Author(s) 2021 OPEN

\begin{abstract}
To promote the development of the western region in China, it is necessary to build an indicator system to scientifically measure the level of sustainable development in Western China. Based on the construction of a sustainable development level evaluation indicator system, this study employs the panel data entropy model to evaluate the sustainable development level of four state-level urban agglomerations in Western China from 2009 to 2018. Then, the geographical detector model is used to measure the spatial heterogeneity degree of the sustainability index and detect the factors influencing the spatial heterogeneity. The results show that (1) the innovation environment and economic growth are the core factors influencing the sustainable development level. (2) The sustainable development level of the cities within the urban agglomerations varies considerably. The sustainability level of central cities and provincial capital cities is significantly higher than that of outlying cities. (3) From the perspective of time, the sustainable development level of the ChengduChongqing urban agglomeration and Guanzhong Plain urban agglomeration shows a rising trend; the Lanzhou-Xining urban agglomeration fluctuates greatly; and the Hohhot-Baotou-Ordos-Yulin urban agglomeration is decreasing. (4) The spatial heterogeneity level of sustainable development among cities in the western urban agglomerations is high, economic factors play a leading role in the spatial heterogeneity of sustainable development, and the western region needs to emphasize regional coordinated development.
\end{abstract}

Keywords Sustainable development · Urban agglomerations · Spatial heterogeneity · Western china

\section{Introduction}

As the pace of global urbanization increases, the proportion of the world's urban population has grown from $30 \%$ in 1950 to $55 \%$ at present [1]. By 2050, 68.4\% of the world's population is expected to live in cities [2]. As urban populations increase, resource consumption, environmental pollution, and the sustainability of cities will experience considerable challenges [3]. Research on urban sustainability is also becoming crucial [4]. As an underdeveloped area in China, the western region lags behind the central and eastern regions owing to backward economic development, poor natural conditions, and unreasonable industrial structures. Therefore, by measuring the sustainability level of urban agglomerations in Western China, this study discusses the various factors that promote or hinder the development of urban agglomerations and proposes a path for the sustainability of urban agglomerations in underdeveloped areas, which would be crucial for realizing the leapfrog development of backward regions and coordinated regional development.

Supplementary Information The online version contains supplementary material available at https://doi.org/10.1007/s43621-021-00012-3.

Yunsheng Zhang, zhangysh17@|zu.edu.cn; Ruomeng Zhou, zhourm18@lzu.edu.cn; Gang Liu, liugang650104@sina.com |'School of Economics, Lanzhou University, Lanzhou 730000, China. ${ }^{2}$ School of Earth Sciences and Engineering, Nanjing University of Information Science \& Technology, Nanjing 210044, China.

Discover Sustainability $\quad$ (2021) 2:1

| https://doi.org/10.1007/s43621-021-00012-3

Published online: 03 February 2021 
Based on urban economic development, urban sustainability must provide wealth for current urban residents but leave room for survival and development opportunities for future urban residents. From the perspective of sustainability, urban sustainability should include the continuous improvement of living standards and continuous optimization and upgrading of urban industrial structures and urban development quality [5] (p.291).

Previous studies on urban sustainability focus on urban ecosystems, emphasizing the need to reduce the harmful effects of economic development on the biosphere [6]. Therefore, industrial transformation and upgrading, ecological industry development, and industrial carbon emissions reduction are considered important means for promoting urban sustainability [7]. As populations move to urban areas, residents' quality of life and cities'livability are becoming important parts of urban sustainability research [8]. Therefore, indicators such as education quality, infrastructure construction, residents' health, and community development are included in urban sustainability indicator systems [9]. At the same time, the relationship between urban innovation capacity and urban sustainability has become increasingly close [10], and technological development as an important part of innovation will be gradually integrated into urban sustainability $[11,12]$. Science and technology will drive urban transformation and provide people with comfortable and convenient urban living environments, thereby becoming the new engine for sustainability $[13,14]$. Furthermore, urban sustainability should focus on issues such as rationalization of government subsidies, urban productivity and efficiency, and balanced regional development [15].

Presently, the internationally recognized sustainability indicator system ISO 37120 includes international indicator standards on urban services and quality of life, with urban residents as the core [16]. This indicator system also covers population and social conditions, sports and culture, urban agriculture and food safety [17-19]. However, few indicators in this system address the potential for sustainability [20]. In addition, owing to data accessibility and integration, data heterogeneity, and the limitations of benchmarking, the operability of existing indicators fails to meet expectations [21]. Moreover, owing to regional differences, these sustainability indicators are not widely used [22] and must be added or removed based on the population, social and economic conditions, and geographic environment of target cities [23].

Compared with other countries, China experiences more complex problems in the process of urban sustainability because Chinese cities have large populations and various types of distributions [24]. China's economy has gradually shifted from scale expansion and factor-driven to efficient, fair and sustainable development [25]. China's urban sustainability is also inclined to reduce inequality and promote the redistribution of wealth [26].

With the rapid promotion of China's urbanization process, the number and size of cities continue to grow, and connections between cities are becoming increasingly close. Urban agglomerations have become mainstream and the trend in urban development [27]. At the same time, urban agglomerations are the most potential and dynamic core areas in China's high-quality development and for the implementation of new urbanization [28]. Therefore, as the main driver of the long-term stable development of the Chinese economy, the sustainability of urban agglomerations will directly affect the quality of the Chinese economy and the country's level of urbanization development [29].

Currently, most evaluations of China's urban agglomerations and urban sustainability focus on central cities'livability, innovation ability, and sustainability, such as in Beijing, Tianjin, Guangzhou [30], and Shanghai [31], or on the Yangtze River Delta (centered around Shanghai) or Middle Reaches urban agglomerations (centered around Wuhan) [32-35]. Few studies have been conducted on cities and urban agglomerations in China's underdeveloped western region. May 17, 2020, The CPC Central Committee and The State Council issued The Guidance on Promoting the Development of the Western Region to Form a New Pattern in the New Era, which means that promoting a new round of sustainable development of the western region will become an important regional strategy of China in the future. Therefore, this study uses national-level urban agglomerations and their internal cities (not including autonomous prefectures) in Western China as a research sample to examine the sustainability path of urban agglomerations in underdeveloped regions.

Based on the Sustainable Development Goals (SDGs) [36], ISO 37120 and other sustainable development indicators that meet China's current national conditions, this study constructs an urban sustainability evaluation indicator system and employs the panel data entropy model to evaluate the sustainable development level of four national urban agglomerations in Western China from 2009 to 2018: the Chengdu-Chongqing urban agglomeration, Guanzhong Plain urban agglomeration, Lanzhou-Xining urban agglomeration and Hohhot-Baotou-Ordos-Yulin urban agglomeration. This paper further uses the Geographical Detector to measure the special heterogeneity of the index and detect the influence of each indicator on the spatial heterogeneity. Finally, we propose an improvement path for sustainable development, which provides an important reference for the comprehensive, coordinated and balanced sustainable development of the Western China urban agglomerations. This paper tries to construct a sustainable development evaluation indicator system for underdeveloped areas in China, analyze the spatial and temporal sustainability evolution characteristics of urban agglomerations in Western China, measure the spatial heterogeneity 
level of their sustainable development index, and find the factors that influence the spatial heterogeneity of sustainable development to provide beneficial suggestions for the future development of western urban agglomerations.

Compared with the existing literature, this study has two main academic contributions. First, this study enriches research on the sustainability level of underdeveloped regions. Second, this paper uses the panel data entropy model to evaluate the samples, which is more reliable than the cross-section and time series models.

This paper is arranged as follows. Section 2 briefly introduces the research area. Section 3 describes the evaluation indicator system, research methods and data sources. Section 4 presents and discusses the evaluation and empirical results, and Sect. 5 concludes the study.

\section{Study area}

An urban agglomeration is a product of a certain stage of urbanization and industrialization development and consists of a group of cities around surrounding areas, with a central city as the core [37]. As of 2020, 10 statelevel urban agglomerations are recognized in China (i.e., the Yangtze River Middle Reaches, Harbin-Changchun, Chengdu-Chongqing, Yangtze River Delta, Central Plains, Beibu Gulf, Guanzhong Plain, Hohhot-Baotou-Ordos-Yulin, Lanzhou-Xining, and Guangdong-Hong Kong-Macao Greater Bay Area). The western urban agglomerations include Chengdu-Chongqing, Guanzhong Plain, Lanzhou-Xining and Hohhot-Baotou-Ordos-Yulin (see Table 1). The proportion in the table is the proportion of the single urban agglomeration index in the whole country. Data are obtained from the Development Plan of Chengdu-Chongqing urban agglomeration, Development Plan of Guanzhong Plain urban agglomeration, Development Plan of Lanzhou-Xining urban agglomeration and Development Plan of Hohhot-Baotou-Ordos-Yulin urban agglomeration and China Statistical Yearbook 2019 [38-41]. Their spatial distribution is shown in Fig. 1.

The Chengdu-Chongqing urban agglomeration is located in Southwest China and is the core area of the Sichuan Basin. The Chengdu-Chongqing urban agglomeration is centered around Chengdu and Chongqing, including 15 prefecture-level cities, namely, Chengdu, Zigong, Luzhou, Deyang, Mianyang, Suining, Neijiang, Leshan, Nanchong, Meishan, Yibin, Guang'an, Dazhou, Ya'an, and Ziyang, in Sichuan Province and Chongqing Municipality. The development of the Chengdu-Chongqing urban agglomeration is crucial for promoting the interaction of the central and western regions, thereby expanding space for economic growth in the western region [42].

The Guanzhong Plain urban agglomeration centers around Xi'an, stretching across Shaanxi, Shanxi, and Gansu Provinces, including 11 prefecture-level cities, such as Xi'an, Baoji, Xianyang, Tongchuan, Weinan, and Shangluo in Shaanxi Province; Yuncheng and Linfen in Shanxi Province; and Tianshui, Pingliang, and Qingyang in Gansu Province. Located in the inland center of China, the Guanzhong Plain urban agglomeration has valuable historical and cultural heritage [43].

The Lanzhou-Xining urban agglomeration is located in the inland region of Northwest China. The Lanzhou-Xining urban agglomeration is centered around Xining and Lanzhou, including five prefecture-level cities, namely, Lanzhou, Baiyin, and Dingxi, in Gansu Province and Xining and Haidong in Qinghai Province. The development of the Lanzhou-Xining urban agglomeration is significant for supporting homeland and ecological security [44].

The Hohhot-Baotou-Ordos-Yulin urban agglomeration is located in the central and western regions of the Inner Mongolia Autonomous Region and centered around Hohhot, including three prefecture-level cities, namely, Baotou, Ordos, and Yulin City, in Shaanxi Province. This region is rich in coal, natural gas, rare earth resources, and other resources [45].

Table 1 Overview of urban agglomerations in Western China

\begin{tabular}{|c|c|c|c|c|}
\hline Name of urban agglomerations & Central cities & $\begin{array}{l}\text { Proportion of } \\
\text { land area (\%) }\end{array}$ & $\begin{array}{l}\text { Proportion of total } \\
\text { population (\%) }\end{array}$ & $\begin{array}{l}\text { Proportion } \\
\text { of GDP (\%) }\end{array}$ \\
\hline Chengdu-Chongqing urban agglomeration & Chengdu, Chongqing & 1.92 & 6.80 & 6.40 \\
\hline Guanzhong Plain urban agglomeration & Xi'an & 1.12 & 2.79 & 2.14 \\
\hline Lanzhou-Xining urban agglomeration & Lanzhou, Xining & 1.02 & 0.86 & 0.66 \\
\hline Hohhot-Baotou-Ordos-Yulin urban agglomeration & Hohhot & 1.82 & 0.82 & 1.91 \\
\hline
\end{tabular}




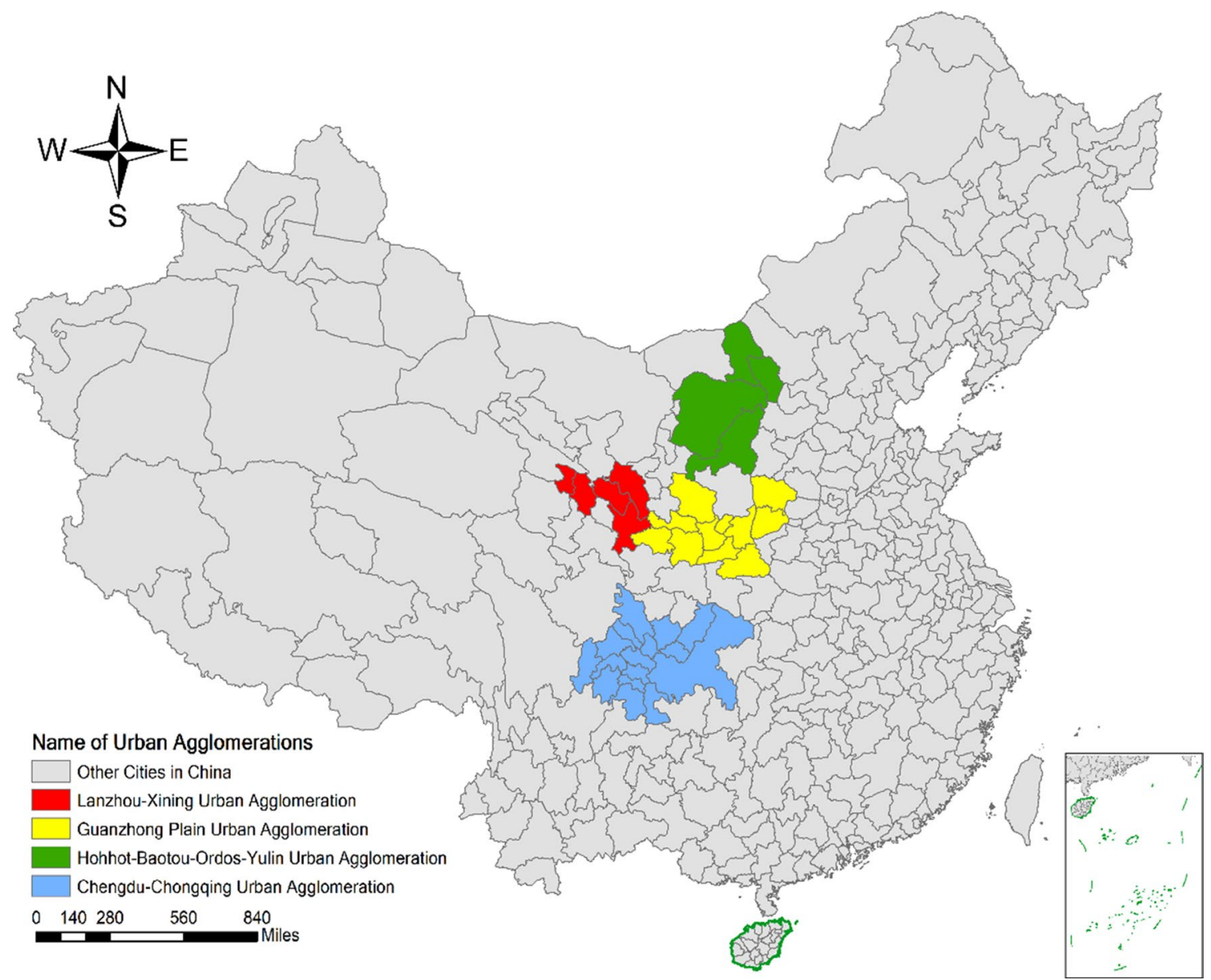

Fig. 1 Schematic diagram of the spatial distribution of the Western China urban agglomerations

\section{Methodology and data}

This section introduces the indicator selection of the evaluation system, the empirical models and the data sources of this paper. This paper mainly includes two empirical models. The panel data entropy method is used to calculate the sustainable development level index, and the geographical detector is employed to measure the spatial heterogeneity level of the index and detect the factors that influence the spatial heterogeneity of sustainable development in Western China's urban agglomerations.

\subsection{Evaluation indicator system}

\subsubsection{Selection of Indicators}

Based on the three dimensions of the triple bottom line [46] for measuring sustainability, namely, economic, social, and environmental sustainability; the SDGs; the ISO 37120 indicator system; requirements for urban sustainability in underdeveloped areas [47], and the development indicators of "innovation, coordination, openness, greenness, and sharing" suitable for the development of Chinese cities [48], this study posits that urban sustainability can be evaluated from three categories and eight aspects, specifically, economic growth, economic structure optimization, urban innovation environment, urban construction, residents' quality, coordinated urban-rural development, human settlement, energy conservation and emissions reduction and living environment. 
3.1.1.1 Economic growth This paper selects Growth Regional Product (GRP)/resident population $\left(X_{1}\right)$ to reflect the value creation of economic growth, as expressed in SDGs 1 and 8; selects total investment in fixed assets/GRP $\left(X_{2}\right)$ to reflect urban investment efficiency, the lower it is, the higher investment efficiency is, which is a negative indicator, which reflects SDGs 8; selects the total retail sales of consumer goods/total population $\left(X_{3}\right)$ to reflect cities' consumption level, as highlighted in SDGs 8 and 12; selects the general public budget revenue/total population $\left(X_{4}\right)$ and disposable income of households/total population $\left(X_{5}\right)$ to reflect the degree of economic achievements sharing. Meanwhile, $X_{4}$ is contained in SDGs 3,8 and 10, and $X_{5}$ is contained in SDGs 1,8 , and 10. Since the central transfer income accounts for a large proportion of the public budget revenue in the western region, the per capita public budget income is added together with the per capita disposable income as an indicator to measure the degree of economic achievement sharing.

3.1.1.2 Industrial structure optimization This paper selects the added value of the tertiary industry/GRP $\left(X_{6}\right)$ and the number of employed persons in tertiary industry/number of employed persons in urban units $\left(X_{7}\right)$ to reflect the quality of the industrial structure. They both are expressed in SDGs 9 and 12.

3.1.1.3 Urban innovation environment This paper uses expenditure for science and technology/general public budget expenditure $\left(X_{8}\right)$ and number of employed persons in scientific research and technical service/number of employed persons in urban units $\left(X_{9}\right)$ to reflect urban innovation input. The number of Patent Applications Granted/total population $\left(X_{10}\right)$ is used to reflect the level of urban innovation ability. They three are specified in SDGs 9.

3.1.1.4 Urban construction We use urban built-up area/total population $\left(X_{11}\right)$ and urban road area/total population $\left(X_{12}\right)$ to reflect the level of urban infrastructure construction, as expressed in SDGs 9 and 11. In some developed countries and China's developed regions, road areas are no longer considered in the measurement of sustainable development levels. However, most cities in western China have relatively low infrastructure construction. Therefore, this paper uses urban road area/total population to measure the level of urban infrastructure construction, as shown in SDGs 9 and 11. At the same time, this paper selects the Number of Hospitals and Health Centers/total population $\left(X_{13}\right)$ to reflect the level of urban medical and health services, as signified in SDGs 3, 9 and 11. Expenditure of urban maintenance and construction fund/GRP $\left(X_{14}\right)$ is selected to reflect the degree of urban construction investment, which represents SDGs 9 and 11.

3.1.1.5 Residents' quality This paper selects expenditure for education/general public budget expenditure $\left(X_{15}\right)$ and number of employed persons in education/number of employed persons $\left(X_{16}\right)$ in urban units to reflect urban education investment, Number of Enrollment Undergraduates in Regular Higher Education Institutions/total population $\left(X_{17}\right)$ to reflect the level of urban education, and total collections in public libraries/total population $\left(X_{18}\right)$ to reflect the degree of social education resources sharing. They all express SDGs $4, X_{17}$ also shows SDGs 8 , and $X_{18}$ is also contained in SDGs 11.

3.1.1.6 Coordinated development of urban and rural areas This paper selects per capita consumption expenditure of rural households/per capita consumption expenditure of urban households $\left(X_{19}\right)$, and per capita disposable income of rural households/Per Capita Disposable Income of Urban Households $\left(X_{20}\right)$ to reflect the coordinated development level of urban and rural areas, as highlighted in SDGs 10; selects urban population/total population $\left(X_{21}\right)$ to reflect urbanization rate, reflecting SDGs 10 and 11 . Because of the large proportion of the rural population in the western cities of China, it is necessary to add these three indicators to measure the level of socially harmonious development.

3.1.1.7 Energy conservation and emission reduction Industrial sulfur dioxide emission/GRP $\left(X_{22}\right)$, industrial waste water discharged/GRP $\left(X_{23}\right)$ and ratio of industrial solid wastes utilized $\left(X_{24}\right)$ are used to reflect the resource utilization efficiency and environmental protection degree in the process of urban industrial production. Meanwhile, $X_{22}$ highlight SDGs 9,12 and 13, and $X_{23}$ and $X_{24}$ both express SDGs 6, 9 and 12 .

3.1.1.8 Living environment This paper uses public buses and trolley buses in operation at year-end/total population $\left(X_{25}\right)$ to reflect the traffic convenience of urban residential environment, as shown in SDGs 11 and 13; uses harmless treatment rate of municipal waste $\left(X_{26}\right)$ to reflect the living environment governance level, and urban green area/urban built-up area $\left(X_{27}\right)$ to reflect the urban greening level. $X_{26}$ and $X_{27}$ are specified in SDGs 11 and 12 and SDGs 11 and 15, respectively.

According to the selection of the above indicators, this paper constructs an indicator system to measure the level of urban agglomeration sustainable development (Table 2 ). 


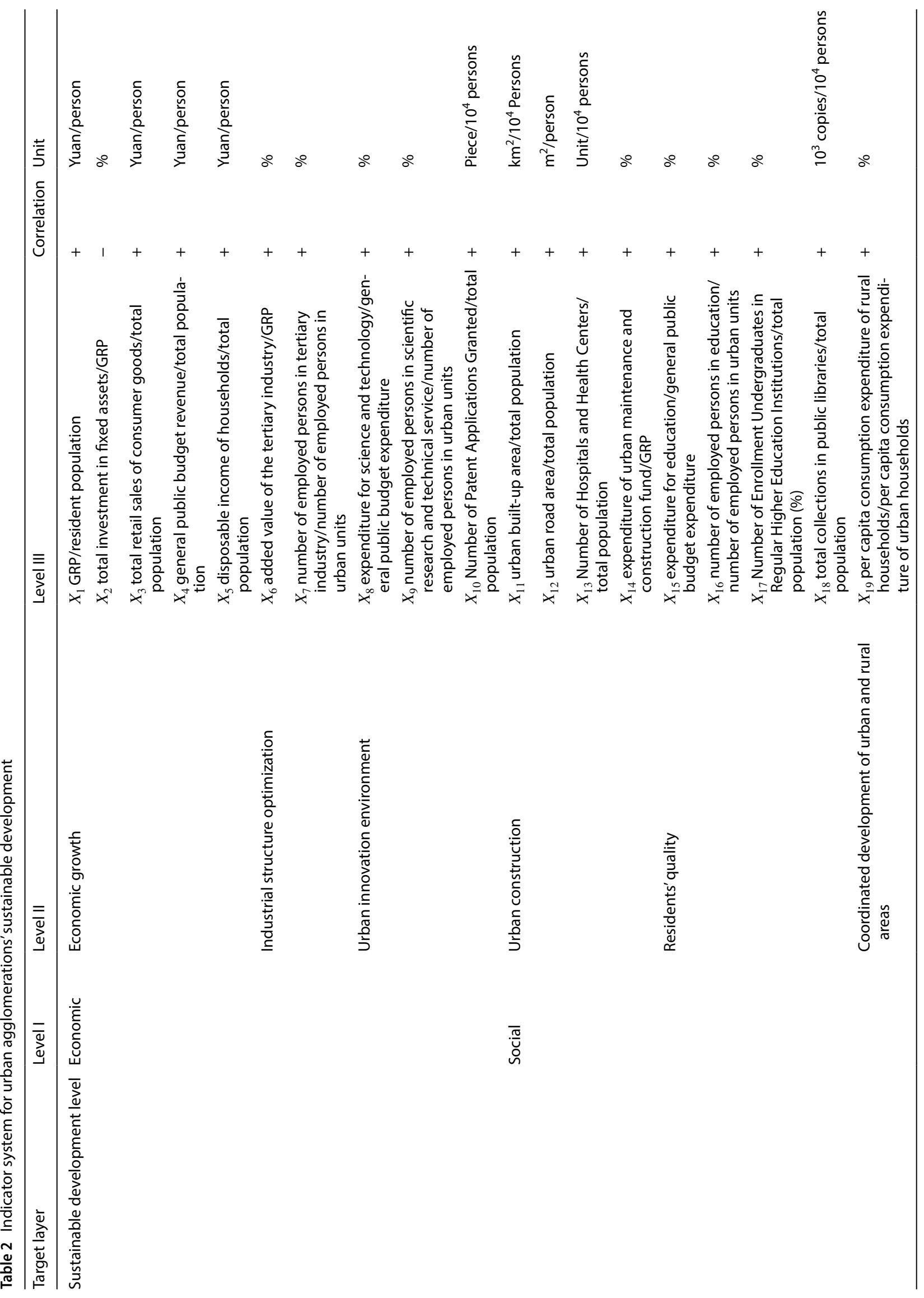




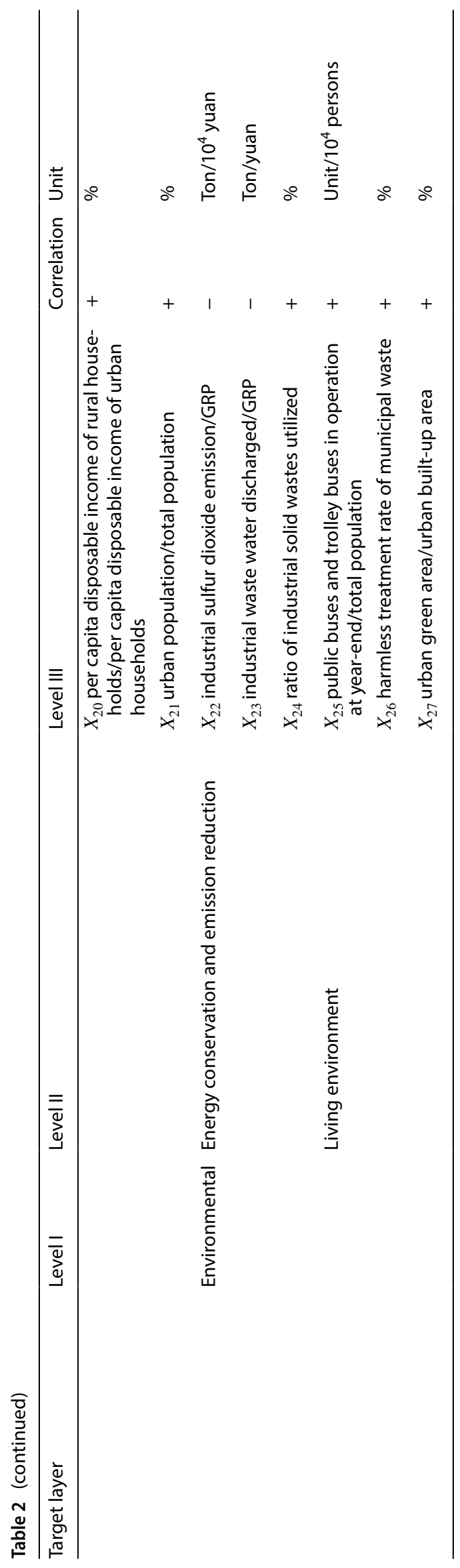




\subsubsection{Reliability test}

In this paper, we use Cronbach's alpha coefficient to test the reliability of the indicator system. Cronbach's alpha evaluates whether the indicators measure the same concept, which reflects the internal consistency of the indicators within the indicator system.

$$
\alpha=\frac{k}{k-1} \times\left(1-\frac{\sum_{j=1}^{K} \sigma_{z_{j}}^{2}}{\sigma_{Z}^{2}}\right)
$$

where, $k$ is the number of evaluation indicators, $\sigma_{z_{j}}^{2}$ is the variance of the $\mathrm{j}$ indicator sample, and $\sigma_{Z}^{2}$ is the variance of the total sample. According to DeVellis's research [49] (p.95), 0.65 is the minimum acceptable value of internal reliability; 0.7-0.8 indicates that the indicator system has a comparable high reliability; and above 0.8 indicates that the indicator system has excellent reliability. This paper chooses cities in Western China's urban agglomerations from 2009 to 2018 as samples. According to formula (1), Cronbach's alpha equals 0.8081 , which is greater than 0.8 . Therefore, this paper's indicator system has ideal internal consistency and reliability, and its assessment result will have high reliability.

\subsection{Panel data entropy method}

In this paper, we use the panel data entropy method to measure the sustainable development level index of urban agglomerations in western China from 2009 to 2018. The entropy method explains the importance of each indicator by the degree of variation of the indicator. The reason why the entropy method is chosen to measure the sustainable development level is that, first, the entropy method is an objective weighting method that avoids the subjectivity caused by artificial weighting. Second, the entropy method reflects the effect of each variable in the evaluation indicator system. The greater the calculated indicator weight is, the greater the variation degree of the indicator is, the more information it provides, and the greater the role it plays in the assessment system. In addition, compared with the traditional crosssection entropy method, this paper adds a time series to construct the panel data entropy model, which obtains more effective sample information and gives a more reasonable and reliable analysis result. The calculation process is as follows:

Step 1: Standardization of indicators. There are $s$ years, $n$ evaluation objects and $m$ evaluation indicators. This study applies the range method to standardize the $j$ indicator $X_{i t j}$ of object $i$ in year $t$ from level III indicators, $t=1, \ldots$, $\mathrm{s}, i=1, \ldots, \mathrm{n}, j=1, \ldots, \mathrm{m}$. The standardized indicator $Z_{i t j}$ is:

Positive indictors:

$$
Z_{i t j}=\frac{X_{i t j}-\min (X)}{\max (X)-\min (X)}
$$

Negative indictors:

$$
Z_{i t j}=\frac{\min (X)-X_{i t j}}{\max (X)-\min (X)}
$$

Step 2: $\quad$ Calculate the proportion $P_{i t j}$ of indicator $j$ from region $i$ in year $t$ :

$$
P_{i t j}=\frac{Z_{i t j}}{\sum_{t=1}^{s} \sum_{i=1}^{n} Z_{i t j}}
$$

Step 3: Weight calculation. First, calculate the information entropy $E_{j}$ of variable j:

$$
E_{j}=-\frac{1}{\ln (s \times n)} \sum_{t=1}^{s} \sum_{i=1}^{n} P_{i t j} \times \ln P_{i t j}
$$

Then, calculate the $j$ variable weight $W_{j}$ : 


$$
W_{j}=\frac{1-E_{j}}{\sum_{i=1}^{m}\left(1-E_{j}\right)}
$$

Step 4: Calculate the sustainable development index $S_{i t}$ of region $i$ in year $t$ :

$$
S_{i t}=\sum_{j=1}^{m} W_{j} \times P_{i t j}
$$

Based on formula (7), $S_{i t}$ is between 0 and 1. The greater $S_{i t}$ is, the better the sustainable development level of urban agglomeration $i$ is in year $t$. By contrast, the smaller the value of $S_{i t}$ is, the worse the sustainable development level of urban agglomeration $i$ in year $t$. We use the level III's $X_{1}$ to $X_{27}$ to calculate each urban agglomeration's sustainable development scores; use the $X_{1}$ to $X_{5}, X_{6}$ to $X_{7}, X_{8}$ to $X_{10}, X_{11}$ to $X_{14}, X_{15}$ to $X_{18}, X_{19}$ to $X_{21}, X_{22}$ to $X_{24}$ and $X_{25}$ to $X_{27}$ respectively to calculate each city group's development index of level II; use the $X_{1}$ to $X_{10}, X_{11}$ to $X_{21}$ and $X_{22}$ to $X_{27}$ separately to get each city group's development scores of level I. Therefore, the sustainable development level of city groups can be ranked according to $S_{i t}$ to analyze the temporal and spatial evolution characteristics of urban agglomerations' sustainable development level in western China.

\subsection{Geographical detector model}

After calculating the sustainable development index, we use the geographical detector model to calculate the spatial heterogeneity level of agglomerations' sustainable development index. Spatial stratification heterogeneity is a geographical phenomenon in which the variance within layers (this paper refers to the inner cities of each urban agglomeration) is less than that between layers (this paper refers to each urban agglomeration). The geographical detector model is a statistical method to detect spatial heterogeneity that can detect the spatial heterogeneity level of single variable $Y$ and the influence of dependent variable $X$ on the spatial heterogeneity of $Y$ [50]. The conditions of using the geographical detector model are that $X$ is a category variable, $Y$ is a numerical variable, the number of layers is greater than 2 , and the samples are not required to be adjacent in space [51]. Meanwhile, the geographical detector can detect both numerical data and qualitative data and has no multicollinearity, which can avoid the endogeneity problem of independent variables and dependent variables [51]. Therefore, this paper employs the geographical detector model to study the spatial heterogeneity level of the sustainable development index of four urban agglomerations and further detects the factors and determinants that affect the spatial heterogeneity of the sustainable development level. In this paper, the spatial heterogeneity degree is calculated by the $q$-statistic of the geographical detector.

$$
q=1-\frac{\sum_{h=1}^{H} N_{h} \times \sigma_{h}^{2}}{N \times \sigma^{2}}
$$

where $h=1, \ldots, H$, is the stratification of the sustainable development index $S_{i}$. This paper uses the Jenks natural break method to discretize $S_{i}$, and the number of layers is stratified based on the discretization. $N_{h}$ is the number of cities within the $h$ layer; $N$ is the number of cities within the western region; $\sigma_{h}^{2}$ is the variance of the sustainable development index of the $h$ layer; and $\sigma^{2}$ is the variance of the sustainable development index of all cities. According to the definition, $q \in[0,1]$. The closer $q$ is to 1 , the more significant the spatial heterogeneity is.

There are $m$ evaluation indicators, and the influence of indicator $j X_{j}$ on the spatial heterogeneity of the sustainable development index is $Q_{j}$.

$$
Q_{j}=1-\frac{\sum_{a=1}^{L} N_{a} \times \sigma_{a}^{2}}{N \times \sigma_{A}^{2}}
$$

where $a=1, \ldots, L$, is the number of layers after discretization of $X_{j}, j=1, \ldots, m$. This paper uses the Jenks natural break method to discretize $X_{j} . N_{a}$ is the number of cities within the $a$ layer; $N$ is the number of cities in the western urban agglomerations; $\sigma_{a}^{2}$ is the variance of the sustainable development index of the $a$ layer; and $\sigma_{A}^{2}$ is the variance of the sustainable development index of all layers. According to the definition, $Q_{j} \in[0,1]$, the larger $Q_{j}$ is, the greater the impact of the indicator on the spatial heterogeneity of sustainable development. If $Q_{j}$ equals $1, X_{j}$ has exactly the same spatial distribution as $S_{i}$ [51].

Hence, this paper uses a geographical detector model to measure the spatial heterogeneity intensity of the sustainable development level of western urban agglomerations and detect the factors and sizes that affect the spatial heterogeneity of sustainable development to explore the coordinated development mode of the western urban agglomerations. 
Table 3 Level III indicators' weight

\begin{tabular}{llllllllll}
\hline Indicator & Weight & Indicator & Weight & Indicator & Weight & Indicator & Weight & Indicator & Weight \\
\hline$X_{1}$ & 0.0368 & $X_{2}$ & 0.0075 & $X_{3}$ & 0.0542 & $X_{4}$ & 0.0941 & $X_{5}$ & 0.0153 \\
$X_{6}$ & 0.0380 & $X_{7}$ & 0.0288 & $X_{8}$ & 0.0627 & $X_{9}$ & 0.0665 & $X_{10}$ & 0.0922 \\
$X_{11}$ & 0.0282 & $X_{12}$ & 0.0260 & $X_{13}$ & 0.0241 & $X_{14}$ & 0.0683 & $X_{15}$ & 0.0146 \\
$X_{16}$ & 0.0254 & $X_{17}$ & 0.0861 & $X_{18}$ & 0.0658 & $X_{19}$ & 0.0108 & $X_{20}$ & 0.0228 \\
$X_{21}$ & 0.0283 & $X_{22}$ & 0.0060 & $X_{23}$ & 0.0062 & $X_{24}$ & 0.0126 & $X_{25}$ & 0.0604 \\
$X_{26}$ & 0.0101 & $X_{27}$ & 0.0082 & & & & & & \\
\hline
\end{tabular}

Table 4 Results of the sustainable development index of urban agglomerations

\begin{tabular}{|c|c|c|c|c|c|c|c|c|}
\hline & \multicolumn{2}{|c|}{$\begin{array}{l}\text { Chengdu-Chongqing urban } \\
\text { agglomeration }\end{array}$} & \multicolumn{2}{|c|}{$\begin{array}{l}\text { Lanzhou-Xining urban } \\
\text { agglomeration }\end{array}$} & \multicolumn{2}{|c|}{$\begin{array}{l}\text { Hohhot-Baotou-Ordos-Yulin } \\
\text { urban agglomeration }\end{array}$} & \multicolumn{2}{|c|}{$\begin{array}{l}\text { Guanzhong Plain urban } \\
\text { agglomeration }\end{array}$} \\
\hline & Index & Growth rate (\%) & Index & Growth rate (\%) & Index & Growth rate (\%) & Index & Growth rate (\%) \\
\hline 2009 & 0.16 & - & 0.22 & - & 0.49 & - & 0.14 & - \\
\hline 2010 & 0.16 & 3.35 & 0.28 & 27.69 & 0.38 & -22.24 & 0.18 & 32.56 \\
\hline 2011 & 0.19 & 14.62 & 0.28 & 2.42 & 0.33 & -14.27 & 0.20 & 13.31 \\
\hline 2012 & 0.21 & 11.12 & 0.29 & 3.37 & 0.33 & -0.59 & 0.17 & -14.01 \\
\hline 2013 & 0.22 & 4.15 & 0.25 & -14.62 & 0.32 & -0.90 & 0.21 & 21.17 \\
\hline 2014 & 0.22 & 1.76 & 0.26 & 5.15 & 0.28 & -12.72 & 0.24 & 11.50 \\
\hline 2015 & 0.22 & 0.62 & 0.33 & 27.60 & 0.21 & -25.90 & 0.23 & -0.39 \\
\hline 2016 & 0.24 & 6.80 & 0.29 & -13.06 & 0.20 & -4.74 & 0.27 & 16.37 \\
\hline 2017 & 0.27 & 11.75 & 0.21 & -29.46 & 0.21 & 6.61 & 0.32 & 16.34 \\
\hline 2018 & 0.30 & 12.62 & 0.26 & 24.45 & 0.15 & -30.99 & 0.30 & -5.67 \\
\hline Average & 0.22 & 7.42 & 0.27 & 3.73 & 0.29 & -11.75 & 0.23 & 10.13 \\
\hline
\end{tabular}

\subsection{Data sources}

The research sample comprises 36 prefecture-level cities and municipality included in four national-level urban agglomerations in Western China. The research time interval is selected from 2009 to 2018. The data for each indicator are from the 2010-2019 China City Statistical Yearbook [52], China Statistical Yearbook [53], China Statistical Yearbook on Environment [54] and 2009-2018 Statistical Bulletin on National Economic and Social Development [55]. All data are accessible at the CElnet Statistics Database, CNKI Statistics Yearbook Database and Qianzhan Database. The data are from districts under cities, and the data of each urban agglomeration are the mean value of the urban data within certain urban agglomerations. Some missing data are smoothed by linear regression.

\section{Results and discussion}

Based on the above evaluation indicator system and panel data entropy method, a comprehensive evaluation is conducted on the sustainable development index of 4 urban agglomerations and 36 prefecture-level cities and municipality in the western region from 2009 to 2018. The indices are shown in Table 4 and Additional file 1: Appendix. The evaluation scores of the level II indicators are shown in Additional file 1: Appendix. The extent of spatial heterogeneity of the sustainability index and the effects on the spatial heterogeneity of the level III indicators are listed in Tables 5 and 6 , respectively.

\subsection{Indicators' weight analysis}

According to formulas (2) to (6), each indicator's weight can be calculated (Table 3). From Table 3, general public budget revenue/total population $\left(X_{4}\right)$, Number of Patent Applications Granted/total population $\left(X_{10}\right)$ and Number of Enrollment 
Undergraduates in Regular Higher Education Institutions/total population $\left(X_{17}\right)$ are ranked the top three. Among the top 10 weighted indicators, there are two indicators used to measure economic growth, three indicators from the urban innovation environment, two measures of residents' quality, and industrial structure optimization. Urban construction and living environment each have one in the top 10. This shows that the sustainable development of the western region relies mainly on economic development, and economic growth and innovation have a great influence on the sustainable development level evaluation indicator system.

The weights of total investment in fixed assets/GRP $\left(X_{2}\right)$, industrial waste water discharged/GRP $\left(X_{23}\right)$ and industrial sulfur dioxide emission/GRP $\left(X_{22}\right)$ are ranked in the bottom three. This result indicates that urban investment efficiency and industrial pollution play little role in the evaluation indicator system. At the same time, the weights of all the indicators in the environmental aspect are low, indicating that the dispersion degree of environmental indicators is small. The reason for this phenomenon is not that the environmental development of the western urban agglomeration has reached its upper limit but that most western cities are unable to take ecological environmental development into account while maintaining economic growth. Therefore, the environmental levels of most western cities are not high, and the differences in environmental indicators are small.

\subsection{Spatial characteristics of sustainable development level}

According to formulas (2) to (7), the sustainable development index of urban agglomerations and cities is calculated. From the perspective of the sustainable development index of urban agglomerations in 2018 (Table 4), the Guanzhong Plain urban agglomeration (0.3000), Chengdu-Chongqing urban agglomeration (0.2986), Lanzhou-Xining urban agglomeration (0.2553), and Hohhot-Baotou-Ordos-Yulin urban agglomeration (0.1461) are ranked from highest to lowest. In terms of the eight dimensions of secondary indicators, the Hohhot-Baotou-Ordos-Yulin urban agglomeration's sustainability levels of economic growth and industrial structure optimization over 10 years are much higher than those of the other three urban agglomerations, but its urban construction (0.0802), residents' quality (0.0559), and energy conservation and emission reduction (0.0066) are all at the last. Its energy conservation and emissions reduction scores are 58 times lower than those of the Lanzhou-Xining urban agglomeration (0.3925). This is because the industrial enterprises in the Hohhot-Baotou-Ordos-Yulin urban agglomeration have been mainly engaged in energy and mineral resources and primary processing for years. Energy and chemical enterprises account for a large proportion of the industrial structure, and industrial pollution is serious, indicating that the current economic growth of Hohhot-Baotou-Ordos-Yulin is still at the expense of the environment. The economic growth (0.1912) and innovation environment (0.0645) of the Lanzhou-Xining urban agglomeration are the lowest among the four urban agglomerations, and its innovation environment is 6 times lower than that of the Chengdu-Chongqing urban agglomeration (0.4433), so its innovation environment needs to be improved urgently. This shows that the sustainable development of western urban agglomerations should pay more attention to increasing innovation capacity, innovation efficiency and the enthusiasm of enterprises, universities and research institutes in the city.

From the perspective of the sustainable development level of each city, first, the top five cities in terms of the sustainable development index over the years, except Mianyang and Ordos, are all provincial capitals and the central cities of urban clusters. For Chengdu-Chongqing, except Chengdu and Mianyang, other cities are not high in the ranking, which also explains why the sustainable development scores of Chengdu-Chongqing are always lower than those of the Guanzhong Plain city group. This indicates that the sustainable development level of the western urban agglomerations is seriously affected by the administrative scale, and the central cities have stronger development advantages compared with the surrounding areas in terms of resource endowment, geographical location, economic structure, and development foundation. Meanwhile, provincial capitals and central cities have a certain polarization effect on the surrounding cities. Second, a further comparison of the eight dimensions of the development index shows that cities with a high index of economic dimensions do not necessarily have a high level $\backslash$ in that of the environment. This is because the population density of Chengdu, Xi'an and other central cities is large, and the urban environmental pressure is also large, which also illustrates that the economic and environmental development in the western region has not yet achieved harmonious growth.

\subsection{Chronology evolution of sustainable development level}

From Fig. 2, it can be found that the sustainable development levels of the four urban agglomerations have different trends over time. In Table 4, the Chengdu-Chongqing urban agglomeration shows a positive growth rate from 2009 to 
Fig. 2 Sustainable development index of urban agglomerations

\section{Legend}

\author{
CC: Chengdu-Chongqing Urban Agglomeration \\ LX: Lanzhou-Xining Urban Agglomeration \\ HB: Hohhot-Baotou-Ordos-Yulin Urban Agglomeration \\ GP: Guanzhong Plain Urban Agglomeration
}

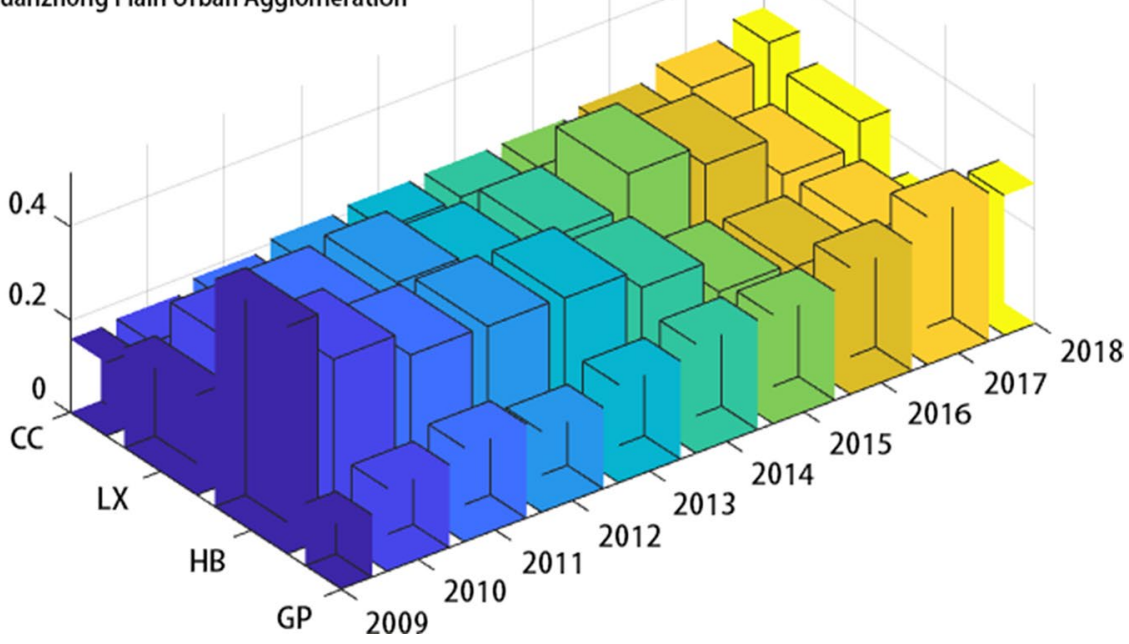

2018, and its sustainable development level has been rising year by year, with excellent performance. In 2010 and 2011, the sustainable development scores of the Chengdu-Chongqing urban agglomeration ranked last, but its sustainable development continued to rise. By 2018, it is only 0.0048 times lower than the Guanzhong Plain urban agglomeration (0.3000), ranking first. From the perspective of the eight dimensions, the two dimensions of Urban Innovation Environment and Energy Conservation and Emission Reduction have the best performance. In terms of the innovation dimension, they are first place except for 2016 and 2017. In addition to 2009 and 2010, the index of energy conservation and emission reduction is also ranked first. This is because in the Chengdu-Chongqing urban agglomeration, Chengdu, as the seat of China's top universities such as Sichuan University, University of Electronic Science and Technology, and Southwestern University of Finance and Economics, has a large number of urban innovation subjects, and the university town supporting industrial park is also mature, so the city has strong innovation ability. Mianyang, China's science and technology city known as the "Silicon Valley of the West", is also a major research and development base for China's defense technology and electronics industry. As the main research and development production base of China's equipment manufacturing industry, Deyang has a very high innovation capacity in the whole western city cluster and even the whole of China. They have all made great contributions to the improvement of the innovation environment and innovation potential of the Chengdu-Chongqing urban agglomeration. This shows that the Chengdu-Chongqing urban agglomeration has a high capacity for innovation, which can not only maintain economic growth but also improve the innovation capacity of enterprises, universities and research institutes, carry out research and development of pollution prevention and control technologies, and improve the pollution treatment rate of industrial industries. The growth rate of the other six dimensions is positive in most years. Therefore, the sustainable development index of the Chengdu-Chongqing urban agglomeration has an obvious rising trend in the time dimension, and the sustainable development level is relatively high.

The sustainable development level of the Guanzhong Plain urban agglomeration is similar to that of the Chengdu-Chongqing urban agglomeration in time, rising from last place in 2009 to first place in 2018. From 2009 to 2011, the sustainable development level of the Guanzhong Plain urban agglomeration is greatly improved, and it falls back to some extent in 2012. After 2013, it entered a significant rising period. In 2015, it decreases slightly, and in 2016 and 2017, it rises to first place, while in 2018, it still remains first place, although there is a slight fall again. Compared with the Chengdu-Chongqing urban agglomeration, the sustainable development level of the Guanzhong Plain urban agglomeration and the exponential change in eight dimensions are not stable enough. From the perspective of the time dimension, the sustainable development level of the Guanzhong Plain is not as good as that of the Chengdu-Chongqing city group.

The sustainable development index of the Lanzhou-Xining urban agglomeration shows a rising trend from 2010 to 2012, decreases in 2013, increases in 2014 and 2015, decreased significantly from 2016 to 2017, and increased again in 2018. The ranking of the sustainable development level of the Lanzhou-Xining urban agglomeration dropped from 
second place in 2009 to third place in 2018. From the perspective of economy, society and economy, the economic index of the Lanzhou-Xining urban agglomeration shows a significant downward trend from 2009 to 2018. This is because Haidong city and Qingyang city both have a high proportion of the public ownership economy, lack of natural resources, and poor economic foundation, so the overall performance of the economic sustainability of the Lanzhou-Xining urban agglomeration is poor [56]. From the perspective of the eight dimensions, only the energy conservation and emission reduction scores have a small change range. There have been sharp declines in economic transformation, urban innovation environment, urban construction, residents' quality and coordinated development of urban and rural areas in 2017. Both the economic growth index and the living environment index dropped significantly in 2018. In general, the sustainable development index of the Lanzhou-Xining urban agglomeration fluctuates greatly. From the perspective of the time dimension, its sustainable development level shows a downward trend, and sustainable development at the economic level needs to be given more attention in the future.

Although the Hohhot-Baotou-Ordos-Yulin urban agglomeration ranks first from 2009 to 2014, its growth rate of the sustainable development level is negative except for a slight increase in 2017. By 2018, its sustainable development level drops to the bottom, indicating that its sustainable development situation is not optimistic. For the Hohhot-Baotou-Ordos-Yulin urban agglomeration, the main drivers of urban development are the stockbreeding and mining industries. The main industries are the upstream industries of manufacturing, with high pollution, high energy consumption and low scientific and technological content. However, at the 17th National Congress of the Communist Party of China in 2008, the party stressed the need to conserve resources and protect the environment. In 2012, the 18th National Congress of the Communist Party of China, the construction of ecological civilization as the future development of China's strategic policy, and put forward to build a high content of science and technology, less resource consumption, less environmental pollution of new industrialization industry, as well as to the future development of China's major innovation as a driving force of decision, therefore, economic, social and environmental index of Hohhot-Baotou-Ordos-Yulin urban agglomeration are in declining trends. In general, the sustainable development level of the Hohhot-Baotou-Ordos-Yulin urban agglomeration is still relatively low, and its model of driving urban development solely by economic growth is not sustainable.

\subsection{Spatial heterogeneity of sustainable development level}

It can be seen from the spatial feature map of the sustainable development index of western China urban agglomerations in 2009, 2012, 2015 and 2018 (Fig. 3), urban agglomerations show similar sustainable development level, Hohhot-Baotou-Ordos-Yulin urban agglomeration gradual homogeneity is the most obvious manifestation, this is because Hohhot-Baotou-Ordos-Yulin urban agglomeration contains less cities, and three of the cities are in Inner Mongolia, so the development level is relatively close to. It can also be seen that although qingyang, Pingliang and Tianhui city belong to the Guanzhong Plain, their sustainable development index is significantly closer to Dingxi and Baiying because the space of the urban sustainable development level index of similarity is mainly based on geographical boundaries as a division, indicating that the sustainable development of Western China cities does not take the urban agglomeration where they are located as the development community but still takes the province where they are located as the main common development unit. The spillover effect of central cities in the western urban agglomeration needs to be further improved.

To further analyze the specific degree of heterogeneity among cities in western urban agglomerations, this paper uses a geographical detector model. We employ the Jenks natural breaks to discretize the index of urban sustainable development level $S_{i}$ into five layers. After that, according to formula (8), the extents of spatial heterogeneity $q$ are calculated (Table 5). The $q$ values from 2009 to 2018 are very close to 1, which demonstrates that the spatial heterogeneity of the sustainable development index of the cities in the four urban agglomerations is at a high level. Moreover, the degree of heterogeneity increased slightly from 2009 to 2018. Although the four urban agglomerations belong to the western region and are geographically close to each other, the differences in the level of sustainable development are obvious due to the different provinces in which they are located, which indicates that the spatial interaction of the level of sustainable development of cities in the western urban agglomerations is not strong.

In addition, a geographical detector is applied to detect which indicator affects heterogeneity. In this paper, natural breaks are used to layer level III's $X_{1}$ to $X_{27}$ in 2018. The number of layers is kept consistent with the number of layers of S. Then, we adjust $X_{j}$ into category variables from grade 1 to grade 5 . According to formula (9), the influence $Q_{j}$ of each indicator on the spatial heterogeneity of the sustainable development index of 2018 is calculated (Table 6). From Table 6, GRP/resident population $\left(X_{1}\right)$, total retail sales of consumer goods/total population $\left(X_{3}\right)$ and Number of Patent 


\section{(a)} Sustainable Develop
2009
\begin{tabular}{|l|}
\hline \\
$\square$ \\
$\square$ \\
$.014200-.016701-.022000$ \\
\hline \\
$.022001-.030700$ \\
$.030701-.048100$ \\
\hline \\
$.048101-.070500$
\end{tabular}
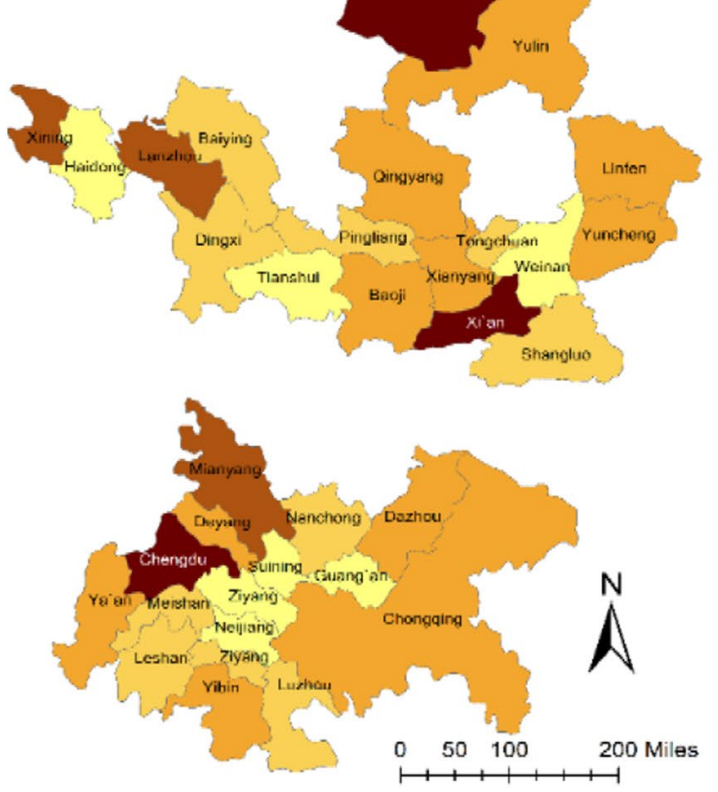

(c)

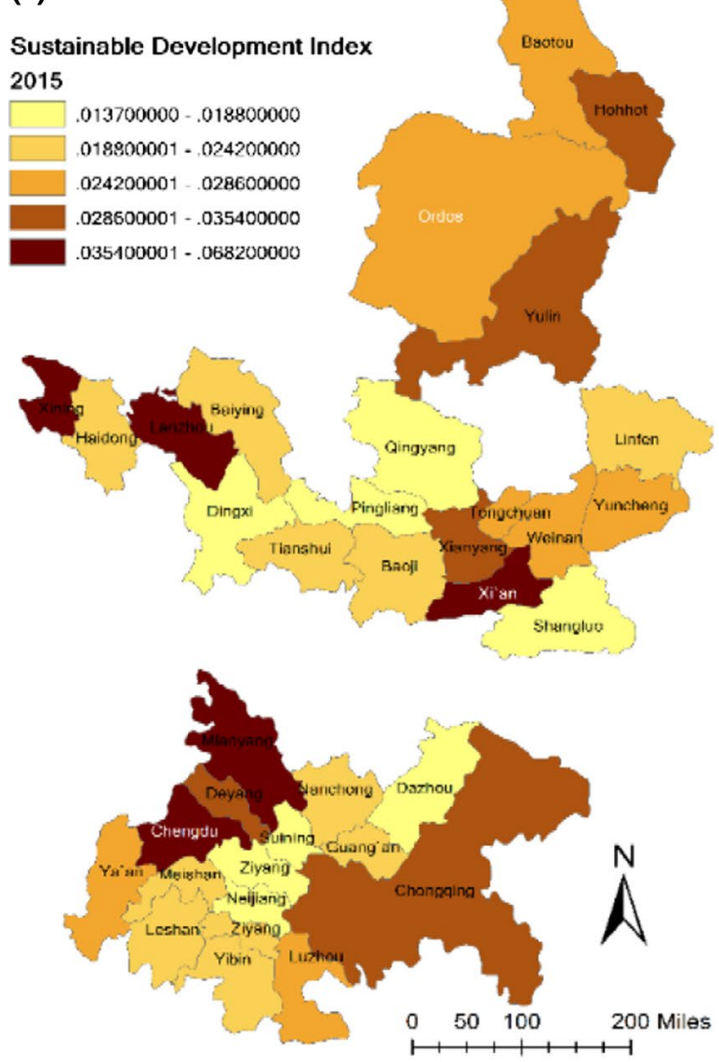

(b)

Sustainable Development Index 2012
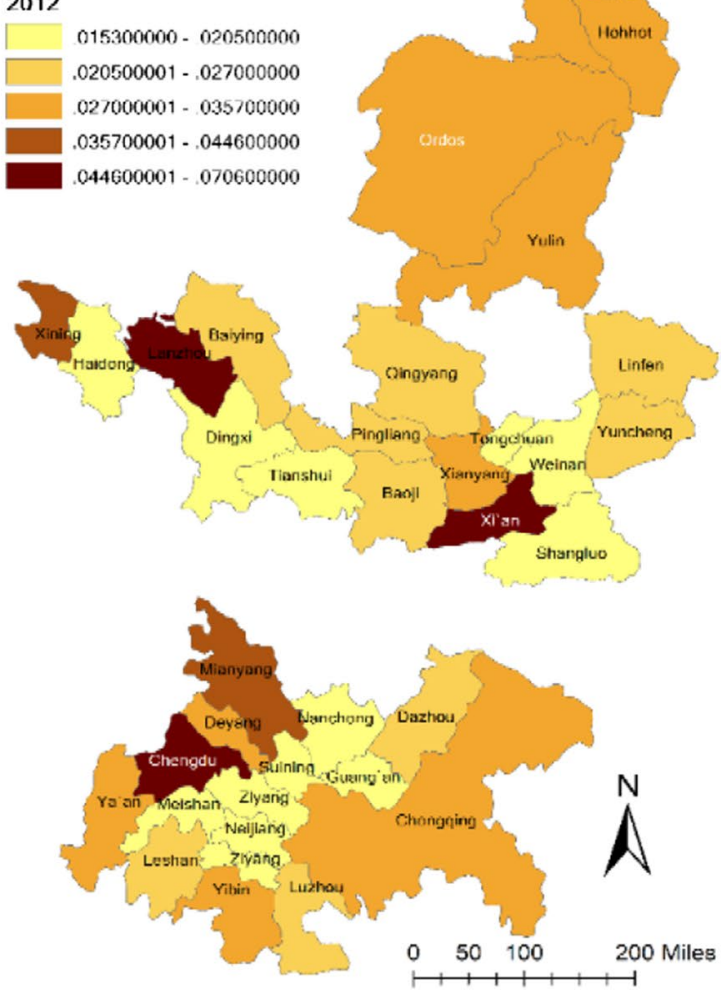

(d)

Sustainable Development Index 2018
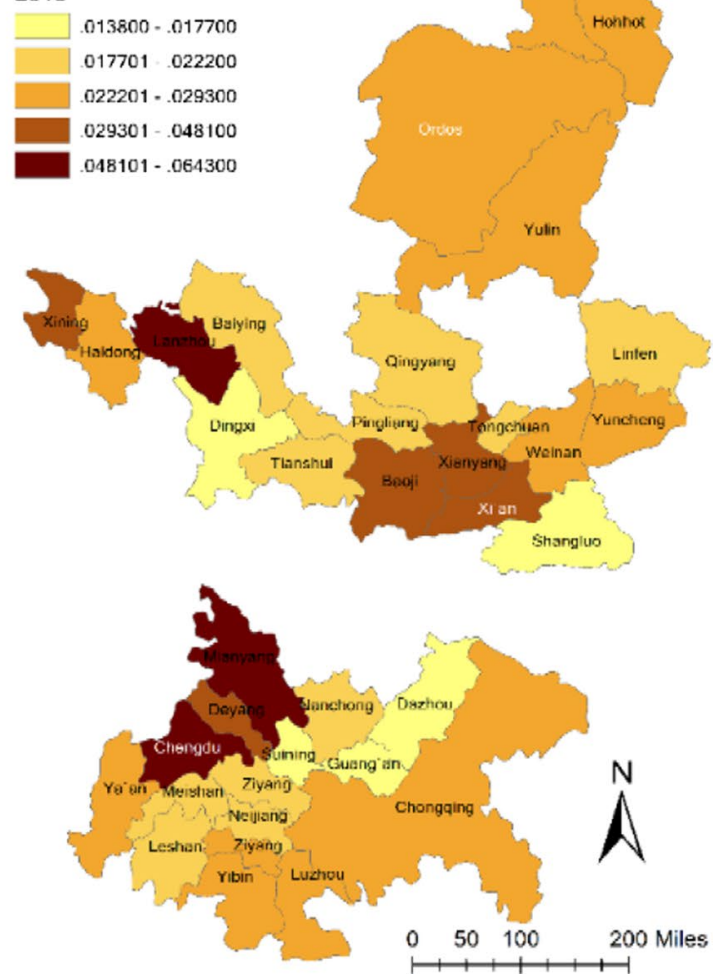

Fig. 3 Schematic diagram of spatial heterogeneity of sustainable development index 
Table 5 The degree of spatial heterogeneity of the sustainable development index

\begin{tabular}{lllllllllll}
\hline Year & 2009 & 2010 & 2011 & 2012 & 2013 & 2014 & 2015 & 2016 & 2017 & 2018 \\
\hline $\mathrm{q}$ & 0.9665 & 0.9353 & 0.9688 & 0.9596 & 0.9761 & 0.9615 & 0.9698 & 0.9710 & 0.9754 & 0.9805 \\
\hline
\end{tabular}

Table 6 Detection results of influencing factors of spatial heterogeneity of sustainable development index in 2018

\begin{tabular}{llllll}
\hline$X_{j}$ & $Q_{j}$ & $X_{j}$ & $Q_{j}$ & $X_{j}$ & $Q_{j}$ \\
\hline$X_{1}$ & $0.6505^{* *}$ & $X_{11}$ & 0.4637 & $X_{21}$ & 0.2355 \\
$X_{2}$ & 0.1182 & $X_{12}$ & 0.4040 & $X_{22}$ & 0.0536 \\
$X_{3}$ & $0.6091^{* *}$ & $X_{13}$ & 0.0151 & $X_{23}$ & 0.0240 \\
$X_{4}$ & 0.4268 & $X_{14}$ & 0.1800 & $X_{24}$ & 0.0329 \\
$X_{5}$ & 0.2185 & $X_{15}$ & 0.0550 & $X_{25}$ & 0.4768 \\
$X_{6}$ & 0.0830 & $X_{16}$ & 0.0700 & $X_{26}$ & 0.1565 \\
$X_{7}$ & 0.0656 & $X_{17}$ & 0.4864 & $X_{27}$ & 0.0827 \\
$X_{8}$ & 0.5132 & $X_{18}$ & 0.2806 & & \\
$X_{9}$ & 0.5387 & $X_{19}$ & 0.0544 & & \\
$X_{10}$ & $0.6419^{*}$ & $X_{20}$ & 0.1536 & & \\
\hline
\end{tabular}

$*^{* *},{ }^{* *}$, and ${ }^{*}$ are significant at the level of $1 \%, 5 \%$, and $10 \%$ respectively

Applications Granted/total population $\left(X_{10}\right)$ have relatively great effects on the spatial heterogeneity of sustainability in Western China. $X_{1}$ and $X_{3}$ explain the spatial heterogeneity to degrees of $65.05 \%$ and $60.91 \%$, respectively, under the significance level of $5 \%$. At the $10 \%$ significance level, the spatial heterogeneity of the sustainable development level is explained by $X_{10}$ to an extent of $64.19 \%$. These results indicate that the main factors influencing the spatial heterogeneity of the sustainable development level are GRP/resident population, total retail sales of consumer goods/total population and Number of Patent Applications Granted/total population. Thus, the economic growth rate, consumption level and innovation capacity decide the sustainable development level to a certain extent in Western China urban agglomerations. This study also finds that the top five factors affecting spatial heterogeneity are all economic variables. Therefore, to achieve coordinated and shared sustainable development in the future, the cities in Western China's urban agglomerations need to enhance the innovation spillover among cities, drive the urban agglomerations to realize innovationdriven development, narrow the economic gap between cities, and improve the economic growth rate of poorer cities.

\section{Conclusion}

This paper takes four state-level city clusters in western China as the research object. The evaluation indicator system of sustainable development is constructed from eight dimensions of Economic Growth, Industrial Structure Optimization, Urban Innovation Environment, Urban Construction, Residents' Quality, Coordinated Development of Urban and Rural Areas, Energy Conservation and Emission Reduction, and Living Environment, using the panel entropy value method, estimates the 2009-2018 sustainable development index of urban agglomeration in the west of China. This paper studies the sustainable development level of urban agglomerations and their inner cities in Western China from two angles of time and space and analyzes the spatial heterogeneity of the sustainable development level among urban agglomerations. The main conclusions are as follows.

First, the innovation environment and economic growth are the core factors influencing the sustainable development level of urban agglomerations and cities. At present, western urban agglomerations can no longer maintain a high level of long-term sustainable development through a single economic growth. Therefore, the western region should improve the overall sustainable development of the region by enhancing the urban innovation environment. Western cities should promote the continuous transformation of industry to technology-intensive and environment-friendly, encourage enterprises to carry out green technology innovation to improve urban innovation capacity, and improve urban energy conservation and emission reduction to make innovation the main driving force for sustainable development of western urban agglomerations.

Second, the differences in the sustainable development levels of cities in the western urban agglomerations are influenced by the administrative rank of cities. The sustainable development index of urban agglomerations shows that 
cities with higher sustainable development levels are mainly provincial capitals. The measurement results show that the central cities have a certain polarization effect on the surrounding areas. In the future, the radiation-driving effect of the central cities on the urban agglomerations should be enhanced so that the central cities and the neighboring cities can develop in a coordinated manner and a reasonable hierarchical system and a coordination mechanism of urban communities with complementary functions can be formed as soon as possible.

Third, in terms of time, the sustainable development levels of the Chengdu-Chongqing urban agglomeration and the Guanzhong Plain urban agglomeration show an upward trend in general; the sustainable development levels of the Lanzhou-Xining urban agglomeration fluctuate more, and the sustainable development of its economic aspect is not stable. The sustainable development level of the Hohhot-Baotou-Erdos-Yulin urban agglomeration decreases year by year, and the development model of relying only on economic growth to maintain the sustainable development index has failed. Therefore, it is necessary to improve the innovation ability of cities, carry out industrial upgrading and explore green development models.

Finally, the spatial heterogeneity of the sustainable development of urban agglomerations is relatively high. The results of the geographic detector $q$-statistic measurement indicate that there is a large extent of spatial heterogeneity in the sustainable development of western urban agglomerations in China. Moreover, the GRP/resident population, total retail sales of consumer goods/total population and number of patent applications granted/total population are main factors affecting the spatial heterogeneity. It should promote exchanges and cooperation between the various urban agglomerations, lessen the level of economic development between cities, reduce the spatial heterogeneity sustainable development levels of the western urban agglomerations, strengthen the urban agglomeration spatial interaction, break the administrative barriers, and promote the flow of resources so that the western region achieves coordinated sustainable development.

Acknowledgements We thank Prof. Xincai Gao for his comments on the early stage of this study.

Authors' contributions Conception (RZ); Writing (RZ); Analysis of data (RZ); Revising (RZ, YZ; GL); Final approval of the version to be published (YZ); Agreement to be accountable for all aspects of the work in ensuring that questions related to the accuracy or integrity of any part of the work are appropriately investigated and resolved ( $R Z, Y Z, G L) . R Z$ gave the substantial contributions to the conception of the work. $R Z$ collected the data. RZ analyzed the data. RZ and $Y Z$ prepared figures. RZ wrote the main manuscript text. RZ, $Y Z$ and $G L$ revised the text. All authors reviewed the manuscript All authors read and approved the final manuscript..

Funding This research was funded by the Fundamental Research Funds for the Central Universities, Grant number: 2019 jbkyxs020.

Data availability The datasets used or analyzed during the current study are available from the first author and corresponding author upon reasonable request.

Code availability The code used during the current study is available from the first author and corresponding author upon reasonable request.

Competing interests The authors declare no conflicts of interest.

Open Access This article is licensed under a Creative Commons Attribution 4.0 International License, which permits use, sharing, adaptation, distribution and reproduction in any medium or format, as long as you give appropriate credit to the original author(s) and the source, provide a link to the Creative Commons licence, and indicate if changes were made. The images or other third party material in this article are included in the article's Creative Commons licence, unless indicated otherwise in a credit line to the material. If material is not included in the article's Creative Commons licence and your intended use is not permitted by statutory regulation or exceeds the permitted use, you will need to obtain permission directly from the copyright holder. To view a copy of this licence, visit http://creativecommons.org/licenses/ by/4.0/.

\section{References}

1. Marvuglia A, Havinga L, Heidrich O, Fonseca J, Gaitani N, Reckien D. Advances and challenges in assessing urban sustainability: an advanced bibliometric review. Renew Sustain Energy Rev. 2020;124:109788. https://doi.org/10.1016/j.rser.2020.109788.

2. Deloitte. Super Smart City 2.0—Artificial Intelligence leads a new trend. 2019. http://pdf.dfcfw.com/pdf/H3_AP201912181371929488 _.pdf. Accessed 23 Sept 2020. 
3. Maranghia S, Parisia ML, Facchinic A, Rubinod A, Kordase O. Integrating urban metabolism and life cycle assessment to analyse urban sustainability. Ecol Ind. 2020;112:106074. https://doi.org/10.1016/j.ecolind.2020.106074.

4. Vojnovic I. Urban sustainability: research, politics, policy and practice. Cities. 2014;41:30-44. https://doi.org/10.1016/j.cities.2014.06.002.

5. Sun J. Urban economics. 1st ed. Beijing: China Renmin University Press; 2016.

6. Zhang X, Li H. Urban resilience and urban sustainability: what we know and what do not know? Cities. 2018;72:141-8. https://doi. org/10.1016/j.cities.2017.08.009.

7. Shah IH, Dong L, Park HS. Tracking urban sustainability transition: an eco-efficiency analysis on eco-industrial development in Ulsan. Korea J Clean Prod. 2020;262:121286. https://doi.org/10.1016/j.jclepro.2020.121286.

8. Guimares JCFD, Severo EA, Felix LA Jr, Da Costa WPLB, Salmoria FT. Governance and quality of life in smart cities: towards sustainable development goals. J Clean Prod. 2019;253:119926. https://doi.org/10.1016/j.jclepro.2019.119926.

9. Secundo G, Ndou V, Vecchio PD, Pascale GD, Phillips F. Sustainable development, intellectual capital and technology policies: a structured literature review and future research agenda. Technol Forecast Soc Chang. 2020;153:119917. https://doi.org/10.1016/j.techfore.2020.11991 7.

10. Feng Y, Zhai J, Ji L. Innovation ability, economic structure and the prosperity and decline of cities. Res Financ Econ Issues. 2019;2019(2):11321. https://doi.org/10.19654/j.cnki.cjwtyj.2019.02.014.

11. Noori N, Hoppe T, Jong MD. Classifying pathways for smart city development: comparing design, governance and implementation in Amsterdam, Barcelona, Dubai, and Abu Dhabi. Sustainability. 2020;12(10):4030. https://doi.org/10.3390/su12104030.

12. Leal Filho W, Wolf F, Lange Salvia A, Beynaghi A, Shulla K, Kovaleva M, Vasconcelos C. Heading towards an unsustainable world: some of the implications of not achieving the SDGs. Discov Sustain. 2020. https://doi.org/10.1007/s43621-020-00002-x.

13. Martin C, Evans J, Karvonen A, Paskaleva K, Yang D, Linjordet T. Smart-sustainability: a new urban fix? Sustain Cities Soc. 2020;45:640-8. https://doi.org/10.1016/j.scs.2018.11.028.

14. Tang Z, Jayakar K, Feng X, Zhang H, Peng RX, Bohlin E. Identifying smart city archetypes from the bottom up: a content analysis of municipal plans. Telecommun Policy. 2019;43:101834. https://doi.org/10.1016/j.telpol.2019.101834.

15. Aina YA, Wafer A, Ahmed F, Alshuwaikhat HM. Top-down sustainable urban development? Urban governance transformation in Saudi Arabia. Cities. 2019;90:272-81. https://doi.org/10.1016/j.cities.2019.03.003.

16. Yang F, Xing L, Liu C, Li Z. Interpretation of international standards of urban sustainable development indicators system. China Econ Trade Herald. 2014;29(8):24-7. https://doi.org/10.3969/j.issn.1007-9777.

17. Yang F, Xu X, Yu K. Analysis of ISO $37120: 2018$, sustainable cities and communities-indicators for city services and quality of life. Stand Sci. 2019;12:18-21. https://doi.org/10.3969/j.issn.1674-5698.2019.12.003.

18. ISO. Sustainable Development of Communities — Indicators for City Services and Quality of Life. ISO 37120. Geneva : International Organization for Standardization. 2014. https://www.iso.org/standard/62436.html. Accessed 5 Sept 2020.

19. ISO. Sustainable Cities and Communities_-Indicators for City Services and Quality of Life. ISO 37120. Geneva: International Organization for Standardization. 2018. https://www.iso.org/standard/68498.html. Accessed 5 Sept 2020.

20. Berman M, Orttung R. Measuring progress toward urban sustainability: do global measures work for arctic cities? Sustainability. 2020;12(9):3708. https://doi.org/10.3390/su12093708.

21. Reisia M, Sabri S, Agunbiade M, Rajabifard A, Chen Y, Kalantari M, Keshtiarast A, Li Y. Transport sustainability indicators for an enhanced urban analytics data infrastructure. Sustain Cities Soc. 2020;59:102095. https://doi.org/10.1016/j.scs.2020.102095.

22. Laslett D, Urmee T. The effect of aggregation on city sustainability rankings. Ecol Ind. 2020;112:106076. https://doi.org/10.1016/j.ecoli nd.2020.106076102683.

23. Steiniger S, Wagemann E, de la Barrera F, Molinos-Senante M, Villegas R, de la Fuente H, Vives A, Guillermo A, Herrera JC, Carrasco JA. Localising urban sustainability indicators: the CEDEUS indicator set, and lessons from an expert-driven process. Cities. 2020;101:102683. https://doi.org/10.1016/j.cities.2020.102683.

24. Ruan F, Yan L, Wang D. The complexity for the resource-based cities in China on creating sustainable development. Cities. 2020;97:102571. https://doi.org/10.1016/j.cities.2019.102571.

25. Zhang J, Hou Y, Liu P, He J, Zhuo X. The goal and strategic path of high-quality development. Manage World. 2019;35:1-7. https://doi. org/10.3969/j.issn.1002-5502.2019.07.002.

26. Puertas J, Bermúdez M. Development of a Global SDG Progress Index Aimed at "Leaving No One Behind." Sustainability. 2020;12(10):4085. https://doi.org/10.3390/su12104085.

27. Zhou G, Chen L, Tang C, He Y, Ran Z. Research Progress and prospects on Changsha-Zhuzhou-Xiangtan urban agglomeration. Econ Geogr. 2018;38:52-61. https://doi.org/10.15957/j.cnki.jjdl.2018.06.007.

28. Fang C, Zhou C, Gu C, Chen L, Li S. A proposal for the theoretical analysis of the interactive coupled effects between urbanization and the eco-environment in mega-urban agglomerations. J Geogr Sci. 2017;27:1431-49. https://doi.org/10.1007/s11442-017-1445-x.

29. Cui M. Comprehensive evaluation of the development quality of urban agglomerations. Stat Decis. 2015;424:61-4. https://doi. org/10.13546/j.cnki.tjyjc.2015.04.017.

30. Li W, Yi P. Assessment of city sustainability_coupling coordinated development among economy, society and environment. J Clean Prod. 2020;256:120453. https://doi.org/10.1016/j.jclepro.2020.120453.

31. Chiu RLH. Urban sustainability and the urban forms of China's leading mega cities: Beijing, Shanghai and Guangzhou. Urban Policy Res. 2012;30:359-83. https://doi.org/10.1080/08111146.2012.737578.

32. Wang X, Xu X. Spatial-temporal evolution and regional disparity of economic high-quality development in the Yangtze River Economic Belt. Econ Geogr. 2020;40:5-15. https://doi.org/10.15957/j.cnki.jjdl.2020.03.002.

33. Xie W. Measurement and countermeasure livable security force of global city for Shanghai-Benchmarking New York, London, Paris, and Tokyo. Resour Dev Mark. 2020;36:561-7. https://doi.org/10.3969/j.issn.1005-8141.2020.06.001.

34. Xiao L, Wu Y. Research on the evaluation and differentiation of urban innovation ability in the Yangtze River Economic Belt-—based on the empirical analysis of 28 prefecture-level cities. Sci Technol Econ. 2020;33:36-40. https://doi.org/10.14059/j.cnki.cn32-1276n .2020.02.008. 
35. Xie S, Deng H. Evaluation on the development quality of urban agglomeration in the middle reaches of the Yangtze River. Stat Decis. 2018;34:55-8. https://doi.org/10.13546/j.cnki.tjyjc.2018.14.012.

36. United Nations. Transforming our World: The 2030 agenda for sustainable development. New York. 2015. https://sustainabledevelopme nt.un.org/post2015/transformingourworld. Accessed 15 Sept 2020.

37. Gu C. Study on urban agglomeration: progress and prospects. Geogr Res. 2011;5:771-84. https://doi.org/10.11821/yj2011050001.

38. National Development and Reform Commission. Development Plan of Chengdu-Chongqing Urban Agglomeration. 2016. https://www. ndrc.gov.cn/fggz/fzzlgh/gjjzxgh/201605/t20160504_1196728.html. Accessed 15 Sept 2020.

39. National Development and Reform Commission. Development Plan of Guanzhong Plain Urban Agglomeration. 2017. https://www.ndrc. gov.cn/xxgk/zcfb/tz/201802/t20180207_962661.html. Accessed 15 Sept 2020.

40. National Development and Reform Commission. Development Plan of Lanzhou-Xining Urban Agglomeration. 2018. https://www.ndrc. gov.cn/xxgk/zcfb/tz/201803/t20180319_962691.html. Accessed 15 Sept 2020.

41. National Development and Reform Commission. Development Plan of Hohhot-Baotou-Ordos-Yulin Urban Agglomeration. 2018. https ://www.ndrc.gov.cn/xxgk/zcfb/ghwb/201803/t20180306_962247.html. Accessed 15 Sept 2020.

42. Ye W, Wu Y. Research on spatial agglomeration effect, spillover effect and coordinated development of Chengdu Chongqing Urban Agglomeration. Res Finan Econ Issues. 2019;430:88-94. https://doi.org/10.19654/j.cnki.cjwtyj.2019.09.011.

43. Wu Y, Luo H, Wang Y. Ecological security measurement of urban agglomeration in Guanzhong plain based on Lotka-Volterra symbiosis model. Bull Soil Water Conserv. 2019;39:230-9. https://doi.org/10.13961/j.cnki.stbctb.2019.06.034.

44. Cheng Q, Zhang Y, Song Y. Research on spatial structure evolution and structural optimization of Lanxi Urban Agglomeration. Areal Res Dev. 2020;39:52-7. https://doi.org/10.3969/j.issn.1003-2363.2020.02.010.

45. Zhuang Y, Xue D, Kuang W, Chi W, Pan T. Study on the pattern of land cover hierarchy in Hohohot-Baotou-Ordos cities in the semi-arid region of China. Remote SensTechnolAppl. 2019;34:197-206. https://doi.org/10.11873/j.issn.1004-0323.2019.1.0197.

46. Elkington J, Trisoglio A. Developing realistic scenarios for the environment: lessons from Brent Spar. Long Range Plan. 1996;29:762-9. https://doi.org/10.1016/S0024-6301(97)82814-2.

47. Ameen RFM, Mourshed M. Urban sustainability assessment framework development: the ranking and weighting of sustainability indicators using analytic hierarchy process. Sustain Cities Soc. 2019;44:356-66. https://doi.org/10.1016/j.scs.2018.10.020.

48. Ma R, Luo H, Wang H, Wang T. Study of evaluating high-quality economic development in Chinese Regions. China Soft Science. 2019; 2019(07):60-67. https://kns.cnki.net/kcms/detail/detail.aspx?FileName=ZGRK201907006\&DbName=CJFQ2019.

49. Devellis RF. Scale development: theory and applications. 2nd ed. California: Sage Publications; 2003.

50. Wang JF, Li XH, Christakos G, Liao YL, Zhang T, Gu X, Zheng XY. Geographical detectors-based health risk assessment and its application in the neural tube defects study of the Heshun Region, China. Int J Geogr Inform Sci. 2010;24(1):107-27. https://doi.org/10.1080/13658 810802443457.

51. Wang JF, Xu CD. Geodetector: principle and prospective. Acta Geogr Sin. 2017;72(1):116-34. https://doi.org/10.11821/dlxb201701010.

52. National Bureau of Statistics. China City Statistical Yearbook. 2019. https://db.cei.cn/. Accessed 15 Sept 2020.

53. National Bureau of Statistics. China Statistical Yearbook. 2019. https://data.cnki.net/. Accessed 15 Sept 2020.

54. National Bureau of Statistics, Ministry of Environmental Protection. China Statistical Yearbook. 2019. https://d.qianzhan.com/. Accessed 15 Sept 2020.

55. Investigation Team of Bureau of Statistics. The Statistical Bulletin on National Economic and Social Development. 2019. https://data.cnki. net/. Accessed 15 Sept 2020.

56. Wei X, Xue Y, Liu J. Research on coordinated dislocation development strategy of Haidong and Xining from the perspective of cultivating and developing metropolitan area. In: 2019 proceedings of China urban planning annual meeting. 2019; 2019:1233-1246. https://doi. org/10.26914/c.cnkihy.2019.046015.

Publisher's Note Springer Nature remains neutral with regard to jurisdictional claims in published maps and institutional affiliations. 